\title{
The Ideotype for Seed Size: A Model Examining the Relationship between Seed Size and Actual Yield in Pea
}

\author{
Jamin Smitchger and Norman F. Weeden \\ Department of Plant Sciences and Plant Pathology, Montana State University, Bozeman, MT 59717, USA \\ Correspondence should be addressed to Norman F. Weeden; nweeden@montana.edu
}

Received 23 December 2017; Accepted 14 March 2018; Published 1 August 2018

Academic Editor: Othmane Merah

Copyright (C) 2018 Jamin Smitchger and Norman F. Weeden. This is an open access article distributed under the Creative Commons Attribution License, which permits unrestricted use, distribution, and reproduction in any medium, provided the original work is properly cited.

\begin{abstract}
Seed size plays a large role in determining productivity of large seeded legumes. In many large seeded legumes such as pea and bean, actual yield, defined here as grain yield at harvest minus the weight of seed planted, is often a better measure of actual productivity than grain yield at harvest, because the weight of planted seed varies with seed size. In many grain legumes, the weight of planted seed can be equal to $10 \%$ of the total grain yield, and minimizing the weight of planted seed could significantly impact actual yield. This study produced an algorithm to examine the relationship between seed size, yield, and actual yield in silico. The output of this algorithm predicted the ideotype for seed size in peas to be much lower ( $12.5 \mathrm{~g} . / 100$ seeds) than the seed size of nearly all commercial varieties, indicating that efficiency in pea cropping systems could be increased by reducing seed size. Modifications to the algorithm would allow the prediction of the ideal seed size in other legumes. The algorithm predicts that there is likely very little correlation between seed size and grain yield, although larger seeded legumes will likely have a higher harvest index. Plant breeders can use the ideotype predicted by this function to create varieties of peas and other large seeded legumes that have higher actual yield. The ideotype for seed size was defined in pea.
\end{abstract}

\section{Introduction}

In dryland production regions, pea yield is mainly limited by summer heat and availability of soil water. Although pea has poor yield stability in dryland cropping systems [1], future yield potential can be estimated based on prior yields, allowing the breeding of advanced cultivars that can thrive in a specific region. Averaged across 2001-2016, the yield potential in Montana, the largest pea production region in the US, is $1735 \mathrm{~kg} / \mathrm{ha}$ [2]. Because environmental conditions are the limiting factor, maximizing economic returns within the constraints of a specific environment is a major breeding objective.

Actual yield as defined here is the weight of seed harvested minus the weight of seed planted. Particularly in large seeded legumes in low yielding environments, yield per se is not a perfect measurement of economic productivity. Given two varieties of peas with the same yield potential $(1735 \mathrm{~kg} / \mathrm{ha})$ but different seed sizes, where variety A has a 100 seed weight of $15 \mathrm{~g}$ and variety B has a 100 seed weight of $30 \mathrm{~g}$, variety A would have $124 \mathrm{~kg} / \mathrm{ha}$ higher actual yield than variety B at current seeding rates of 80 seeds $/ \mathrm{m}^{2}$. Actual yield is a better measure of productivity than the common measurement of grain yield at harvest because it accounts for seed cost. Given seeding rates for pea of $170 \mathrm{~kg} / \mathrm{ha}$ and an average crop yield of $1735 \mathrm{~kg} / \mathrm{ha}$ ), the ratio between harvested grain and seeds planted (harvest ratio) is approximately 10:1. Based on current seeding rates and yields, actual crop yield declines $0.46 \%$ with every $1 \mathrm{~g}$ increase in hundred seed weight. Chickpeas, beans, and other large seeded legumes also have a similar harvest ratio, especially in many dryland cropping systems. This ratio is low compared to most other crops. Camelina and canola, for example, have a harvest ratio of $\sim 500: 1$, and wheat has a harvest ratio of $\sim 40: 1$ (assuming a seeding rate of $78.5 \mathrm{~kg} / \mathrm{ha}$ and 50-bushel grain yield).

Yield potential is the genetically determined ability of a crop to generate optimal yield in a given growth environment [3]. Yield potential is thought to be partially determined by 
seed size, and numerous studies have tried to understand the relationship between seed size and yield in pea and other pulses with contradictory results $[1,4-9]$. A lack of correlation between seed size and yield was found in grass pea under drought conditions [5]. In chickpea, a positive correlation was found between seed size and yield, but no effect was seen in lentil [4]. In one study in pea, a strong correlation was found between seed size and yield [6], and Krajewski et al. [8] found that seed size was positively correlated with yield, explaining $20 \%$ of the variation in yield in pea. However, peduncle number explained nearly $50 \%$ of the variation in yield, indicating that seed size is not the most important factor in determining seed yield. Other research has also shown a correlation between the number of fertile nodes and seed yield rather than seed weight and seed yield [10]. Timmerman-Vaughn et al. [1] indicated that seed size is negatively correlated with seed yield, contradicting the study by Krajewski et al. [8], and Irzykowska and Wolko [7] indicated that QTLs for seed size and yield were not colocated. Gambin and Borras [11] concluded that crop yield within a species was more related to variations in seed number than in seed weight. Hence, there appears to be no consensus regarding the relationship, and the ideotype as defined by Donald [12] for seed size in pea has not been defined.

The theoretical effect of seed size on grain yield is positive because larger seeded peas have a higher harvest index than smaller seeded peas (when all other factors are held constant). There may be an association between low pod wall proportion and high seed yield [13], but seed weight did not seem to affect yield in this study. Pate et al. [3] in a previous study in lupin estimated that for every 100 units of carbon imported from the parent plant into pods or seeds, 52 are incorporated into seeds, 37 are into the pod, and the remaining 11 units are lost as $\mathrm{CO}_{2}$, indicating that up to $41.5 \%$ of photosynthate may end up in pod material. However, $96 \%$ of the nitrogen in the mature fruit is incorporated into seeds, with $16 \%$ of that being remobilized from pod material, indicating that seeds may be more nutrient rich than pods. Pate et al. [3] indicated that approximately $7 \%$ of carbon is photosynthesized from the pod itself. Flynn and Pate [14] indicated that approximately an eighth of the carbon in seeds $(2 \mathrm{mg} /$ photoperiod after 10 days after anthesis) is synthesized from pods and that many of the nutrients in pod tissues are transported to the seed prior to senescence.

When compared to other legumes, peas have a much lower proportion of pod walls to percent pod biomass, and it is estimated that this percentage is around 13\% [13]. A hypothetical plant that could produce $100 \mathrm{~g}$ of seed could produce 400 seeds that weighed a $0.25 \mathrm{~g}$ or 100 seeds that weighed $1 \mathrm{~g}$ [15]. However, in reality the amount of photosynthate required to create $1 \mathrm{~kg}$ of small seeded peas is higher than that required to create $1 \mathrm{~kg}$ of large seeded peas because small seeded peas require more pod surface area per unit of mass and more flowering nodes in order to produce the same amount of yield. Therefore, smaller seeded varieties may have an inherent theoretical disadvantage in achieving high grain yields. The consideration of the plasticity of yield components is important when determining the trade-offs between seed size and seed number [15]. Assuming that pod wall thickness is the same in large seeded and small seeded genotypes and that pod length is the same, we can determine the relative amount of photosynthate required to produce pods and seeds of a certain size. Pod material is photosynthetic so it may not be a major burden for the plant to produce, but pods are a sink during their formation [14]. Grain yield is associated with harvest index, which is the ratio of grain yield to plant biomass. This source-sink relationship in peas is dependent on seed size, pod length, plant height, leaf size, stem width, stem wall thickness, leaf thickness, stipule size, and other factors. Here we develop a mathematical model to examine the effect of pod length and seed size on the proportion of photosynthate available for partitioning into seed and pod material. All other parameters of harvest index were assumed to be fixed, and only pod size and seed size were varied.

\section{Materials and Methods}

The functions to predict the ideal pod length and ideal seed size were created in Excel spreadsheets. All of the equations were derived from commonly used mathematical concepts.

2.1. A Function to Predict the Ideal Pod Length. The formula for the surface area of a cylinder $\left(\mathrm{SA}=2 \pi \mathrm{r}^{2}+2 \pi \mathrm{rh}\right)$ allows the prediction of total pod surface area per plant when pod length is varied. Yield, seed size, spacing of seeds in the pod, and all other parameters were held constant. It is assumed that pea pods have the basic shape of a cylinder. Seed radius ( $\mathrm{r}$ in the formula) is held constant and only pod length is varied. Thus, seed number is fixed, and the number of pods per plant will vary with pod length. For example, if a $4 \mathrm{~cm}$ pod holds 5 seeds and the yield potential is fixed at 100 seeds in the model, the plant will produce 20 pods. The surface area of the twenty pods based on the formula for the surface area of a cylinder is $188.4 \mathrm{~cm}^{2}$. Changing the pod length to $8 \mathrm{~cm}$ will increase the number of seeds per pod, and only 10 pods will be needed to have the same yield potential. The surface area of the 10 pods is $172.7 \mathrm{~cm}^{2}$. The pod surface area was compared between long-podded and short-podded pea to determine the ideotype for pod size.

2.2. A Function to Predict the Ideal Seed Size. The core of the ideal seed size model is the equation for actual yield (yield per acre, seed planted). A number of equations (see below) are used to increase the theoretical accuracy of the model by predicting changes in harvest index based on seed size. The algorithm is based on the idea that increasing harvest index will result in increased yield, a trend which is commonly seen in other crops [16]. This algorithm did not account for variation in other factors besides seed size.

\subsection{Assumptions of the Function to Predict the Ideal Seed Size}

(i) The density of a dry pea seed is $1.176 \mathrm{~g} / \mathrm{cm}^{3}$, which was empirically determined in this study from a single large sample of dry pea seed. 
(ii) The density of a dry pea pod is approximately $1.05 \mathrm{~g} / \mathrm{cm}^{3}$, which was empirically determined from a single sample of pea pods.

(iii) Seed weight (which also influences pod size and pod number when the yield potential is held constant) is the only characteristic of a plant that varies.

(iv) The amount of photosynthate available to produce either pods or seeds is fixed at a specified yield potential dependent on specific environmental factors.

(v) Formulas for the surface area and volume of a cylinder are a good approximation of the shape of a pea pod. This model does not account for the portion of the tip and base of the pod not occupied by seed.

Several other assumptions will be identified and discussed in the Results and Discussion.

The function to determine the ideal seed size uses the following equations: each one of the parameters is a column title in the Excel spreadsheet found in supplementary data and explains the underlying calculations occurring.

Seed planted per acre: ((seeding rate $\left./ \mathrm{m}^{2}\right) /(\mathrm{sq}$. feet per $\left.\left.\mathrm{m}^{2}\right)\right) *($ square feet in an acre).

Seed cost multiplier (cost of seed planted per lb/value of harvested grain per $\mathrm{lb}$ ). This accounts for the difference in value between seed grown by the farmer and seed purchased by the farmer.

Mass per seed (Mass): 100 seed weight/100. This can be varied or held constant at a specific value in order to determine the ideal seed weight.

Volume of a seed: (Mass)/(seed density). Seed density is approximately $1.176 \mathrm{~g} / \mathrm{cm}^{3}$.

Radius of a seed (r): the radius of a seed is found by using the formula for the volume of a sphere (volume = $\left.4 / 3 \pi r^{3}\right)$ and solving for the radius. Therefore $r=\{($ Volume $) /$ $((4 / 3) * \pi)\}^{1 / 3}$.

Seed diameter (Seed Diam): 2 times the radius.

Pod length: this can be varied in the model or held constant at a specific value. Pod length is generally about 6 $\mathrm{cm}$ in peas, but this varies depending on the variety. This parameter affects seeds per pod, and pod number.

Correction for space between seeds in a pod: this accounts for the fact that there is often space between the seeds in a dry pod. The multiplier, which represents the actual space taken up by the seed divided by the dry seed diameter, accounts for the pod wall material required to produce a seed if the seed actually requires more space in the pod than its dry seed diameter. It should be noted that the multiplier increases pod material by decreasing the number of seeds per pod. Therefore, more pods must be produced if there is more space between seeds. Seed yield will likely decrease if more photosynthate is partitioned into pod material versus seed material.

Pod width: seed diameter $+2 \mathrm{x}$ pod wall thickness. Pod wall thickness was determined empirically to be approximately $0.194 \mathrm{~mm}$ on average.

Photosynthate: this is the total amount of sugars and other nutrients available for partitioning into seeds, seed testa, and pods (in units of grams per plant). This parameter is held constant at an arbitrarily determined value. The algorithm assumes that pea plant sizes, leaf number, and other factors are the same. Only seed size and a few other yield parameters are varied. The percentage of photosynthate dedicated to seeds or pods will vary depending on seed size and pod number. It is quite often that pea plants have enough energy to create about $20 \mathrm{~g}$ of pod wall material, seeds, and seed testa, based on empirical data. Photosynthate $(\mathrm{g})=($ mass per seed $*($ length of pod/ radius of seed $) *$ pod number $)+\left(\right.$ pod number $*\left(\pi \mathrm{r}_{1}{ }^{2} \mathrm{~h}-\pi \mathrm{r}^{2} \mathrm{~h}\right) *$ pod density in $\mathrm{g} / \mathrm{cm} 2)$. In this case $\mathrm{h}=$ pod length, $\mathrm{rl}=$ pod width, and $\mathrm{r}$ = seed diameter. This equation can be partitioned into two components where (mass per seed $*$ ((length of pod/ radius of seed)*pod number)) is the seed yield component and (pod number $*\left(\pi \mathrm{r}_{1}{ }^{2} \mathrm{~h}-\pi \mathrm{r}^{2} \mathrm{~h}\right) *$ pod density in $\left.\mathrm{g} / \mathrm{cm} 2\right)$ is the pod weight component. The percentage of photosynthate being directed toward the seed or pods for any seed weight can be determined by dividing the seed yield component or pod weight component by the total weight of photosynthate.

Pod number based on amount of photosynthate produced $(\operatorname{Pod} \#)$ : this the number of pods per plant. It is important to note that, to produce the same amount of photosynthate per plant, pod number must vary when seed size varies. Pod number can be determined with the following formula. Pod $\#=$ photosynthate/ $\{$ (mass per seed $*$ (h / seed diameter $))+\left(\left(\pi \mathrm{r}_{1}{ }^{2} \mathrm{~h}-\pi \mathrm{r}^{2} \mathrm{~h}\right) *\right.$ pod density $\left.)\right\}$. In this case $\mathrm{h}=$ pod length, $r_{1}=$ half of the pod width, and $r=$ seed radius. Photosynthate is held constant at an arbitrary value (10 g), and the weight of photosynthate is divided by the weight of a pod at a given seed size.

Amount of photosynthate allocated to seed: this is number of grams of photosynthate that is allocated to the seed and not allocated to the pods. The amount of photosynthate allocated to the seed is dependent on seed size and pod length. The equation for the amount of photosynthate allocated to seed $=$ Mass $*(\operatorname{Pod}$ L/Seed Diam $) *$ Pod\#.

$\%$ Allocated to seed: (photosynthate allocated to seed/photosynthate) $* 100$.

Expected yield potential: this will vary depending on the environment and location. According to the National Agricultural Statistics Service the average yield in Montana during the 15-year period between 2001 and 2016 was 1735 $\mathrm{kg} / \mathrm{ha}$.

Expected weight of yield components: this is the total weight of pods, seed, and seed testa produced by a specific plant. The relative proportion of pods, seeds, and seed testa is dependent on seed diameter, and the total amount of pod material is required to achieve specific yield potential decreases with increases in seed size. All other factors are held constant. In general, the weight of seed is $85 \%$ of the weight of the total weight of all the yield components, so the expected yield in Montana ( $1735 \mathrm{~kg} / \mathrm{ha}$ ) is divided by .85 . The expected weight of yield components is held constant in the seed size model, but the number is dependent on expected yield.

Yield at harvest: the expected yield at harvest of seed given a specific seed weight. Yield at harvest $=(\%$ Allocated to seed/100) $*$ Expected weight of yield components. Expected 
yield at harvest increases with increasing seed weight because less photosynthate is going to pod weight.

Actual seed yield: yield at harvest minus the weight of seed planted. This is essentially parabolic. It reaches a high point at the ideal seed weight and then starts to decline.

Volume of seed that is occupied by the testa: This is part of the volume of a seed that is composed of the seed coat. The seed coat (testa) is the outer surface of the seed, and it is often stripped from the seed during processing. It was empirically determined in this study that the seed testa has an average thickness of $0.0125 \mathrm{~cm}$. The volume can be found by determining the volume of a seed and subtracting the volume of the seed without its testa. Volume of testa $=4 / 3 \pi r_{1}{ }^{3}-4 / 3 \pi r^{3}$. In this case $r_{1}=$ seed radius, and $r=$ seed radius minus testa thickness.

Mass of testa: volume of testa $*$ seed density. It is possible that the testa may be more or less dense than a whole seed, but it sinks in water, indicating that it has a density over $1 \mathrm{~g} / \mathrm{cm}^{3}$.

Actual seed yield minus testa: seed mass - mass of testa.

Number of $g$ of seed: the number of grams of photosynthate dedicated to the seed without its testa.

Percent of photosynthate going to seed without its testa: (number of $\mathrm{g}$ of seed/photosynthate) $* 100$.

Yield minus the weight of seed testa: expected weight of yield components $*$ Percent of photosynthate going to seed without its testa.

Weight of seeds planted with varying 100 seed weights: (total seeds per acre* Mass per seed) $*$ the number of grams per pound (there are $453.59237 \mathrm{~g}$ per lb).

\section{Results and Discussion}

Our mathematical algorithm (results shown in Figure 1) was created to predict the ideotype for pod length. This function shows the relationship between pod surface area per plant and pod length.

It should be noted that increasing pod length also increases the number of seeds per pod, reducing the number of pods needed per plant to reach a given yield potential. Increases in harvest index are the major mechanism by which increases in pod length increase theoretical yield. The function for pod length predicts longer pods are a more efficient use of plant material than shorter pods. Shorter pods with fewer seeds per pod require more pod ends to reach the same yield potential as a longer podded variety. As a result, the surface area of pod material for a given yield potential declines with increased pod length. However, the plant may not always have enough photosynthate to create longer pods. In peas, average pod length is approximately 6 $\mathrm{cm}$ based on data collected in this study, but this number will differ in various germplasm. The ideal pod length would need to be determined empirically, but this model indicates that the ideotype of pea is a plant with longer pods since it would be a more efficient use of plant material. However, the current average length of pods $(6 \mathrm{~cm})$ is already nearly ideal. Therefore, pod length should not be an important target for breeders, although increasing pod length in shortpodded lentil and chickpea would theoretically increase harvest index.

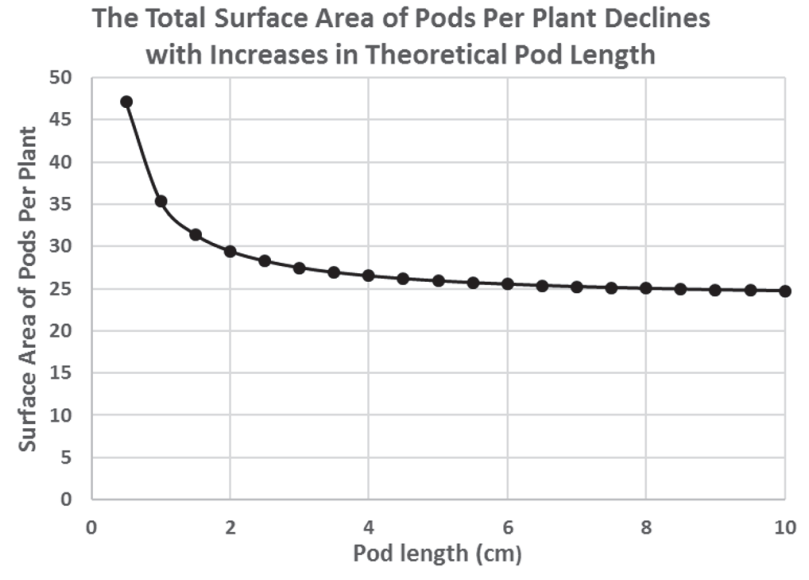

Figure 1: Pod length and pod surface area (assuming a seed yield per plant of 15 seeds and a $0.5 \mathrm{~cm}$ seed diameter).

\section{The Ideal Seed Size for Pea based on Actual Seed Yield}

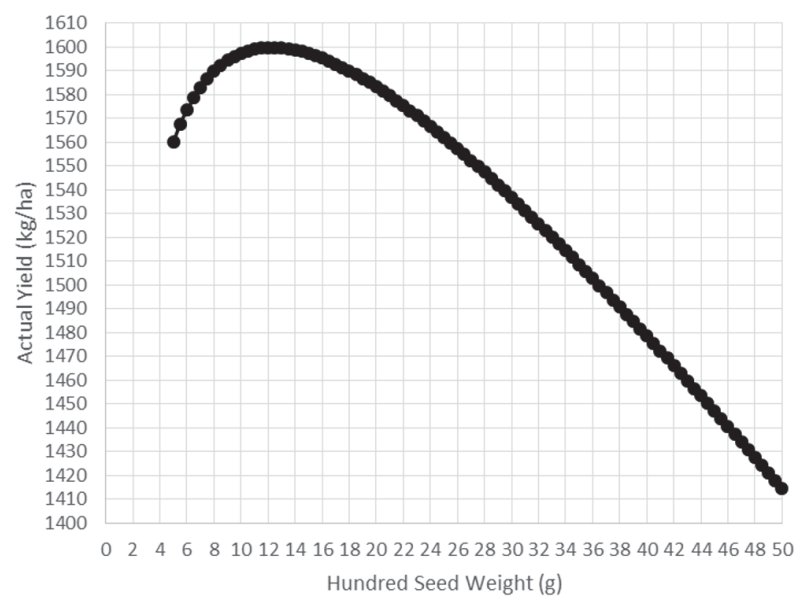

FIgure 2: The ideal seed size for pea in Montana. The ideal seed size is at the vertex of the curve.

The function for seed size was created in a Microsoft Excel spreadsheet (the equation predicting the ideal pod length is on the first sheet of the spreadsheet). The Excel spreadsheet containing the algorithm predicting the ideal seed size in pea can be viewed electronically at https://zenodo.org/record/ 1189038\#.WudMIaQvyUk and is also available in supplementary data. The DOI for the file is $10.5281 /$ zenodo.831165. If trouble is encountered opening the spreadsheet, the spreadsheet is also available by contacting the author. Once the spreadsheet is opened, yield potential, seed cost, pod length, or seeding density can be changed to a single value in all the cells in any green column and the effect on ideal seed size can be visualized. This function was used to predict an ideal 100 seed weight based on a yield potential of $1735 \mathrm{~kg} / \mathrm{ha}$ and a seeding rate of 80 seeds $/ \mathrm{m}^{2}$ (Figure 2). This weight was determined to be $12.5 \mathrm{~g}$, but yield varies only slightly when a given seed weight is near the vertex of the curve. Therefore, 


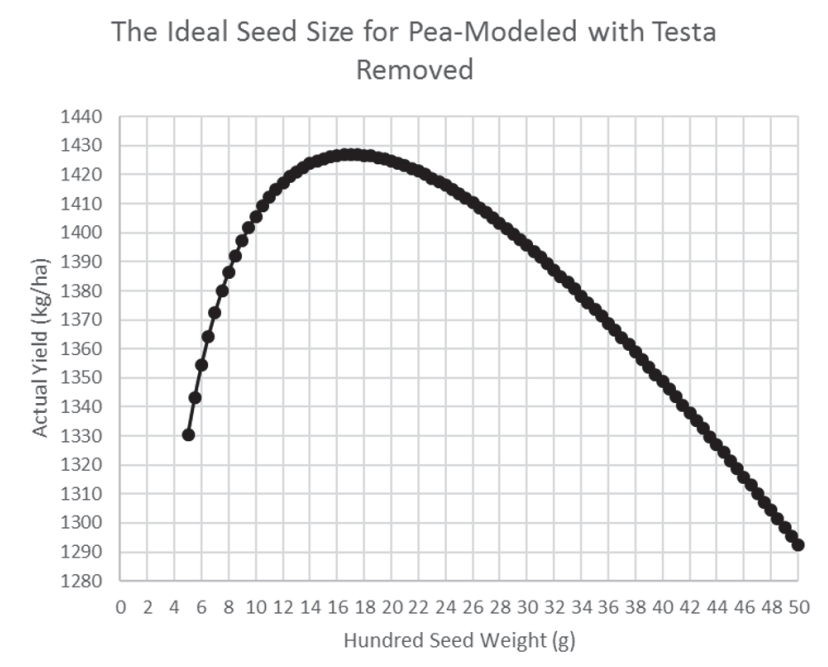

FIGURE 3: The ideal seed size for pea-modeled with seed testa removed. The ideal seed size is at the vertex of the curve.

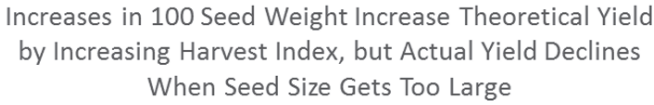
When Seed Size Gets Too Large

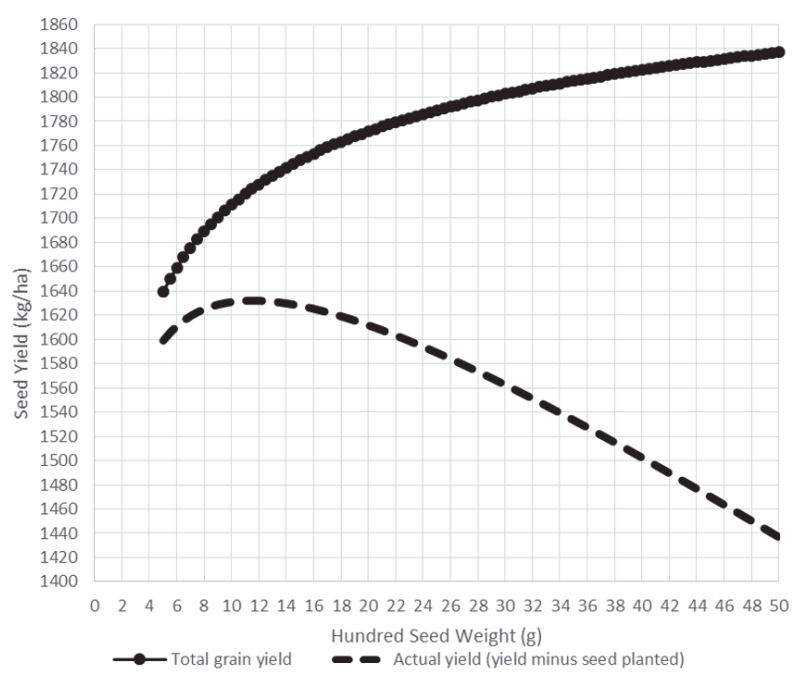

Figure 4: The contrast between the weight of the grain harvested and actual yield (grain harvested minus seed planted) as seed size increases.

the ideal 100 seed weight may be better estimated as a range from 8.5 to $16 \mathrm{~g}$.

We also used the function to predict the ideal 100 seed weight with the testa removed (assuming no value for the seed testa) to be $\sim 17.5 \mathrm{~g}$ based on a yield potential of $1548 \mathrm{lb} / \mathrm{A}$ and a seeding rate of 80 seeds $/ \mathrm{m}^{2}$ (Figure 3 ).

Finally, the relationship between 100 seed weight and theoretical (total) yield versus actual yield is presented in Figure 4. Theoretical yield, which is typically reported in agricultural summaries, continues to increase with 100 seed weight, but fails to indicate that a portion of that yield must be subtracted as planting inputs. The net actual yield reaches an apex and then declines after a certain seed size is passed.
Several assumptions involved with the overall algorithm need further discussion to clarify their effect on the function should the assumption prove inaccurate. The function is most sensitive to seeding rate and expected grain yield. Halving the seeding rate will increase the ideal 100 seed weight from $12.5 \mathrm{~g}$. to $20 \mathrm{~g}$. Doubling expected grain yield from 1735 to $3470 \mathrm{~kg} / \mathrm{ha}$ will also increase the ideal 100 seed weight to $20 \mathrm{~g}$. The values used in the function are based on years of data from Montana sites but can be easily modified to other locations with a history of growing pulses. The assumption that the amount of photosynthate available to produce either pods or seeds is equal may be debated because it is likely that less photosynthate is required to produce $1 \mathrm{~g}$ of pod versus $1 \mathrm{~g}$ of seed, seeds being enriched in nutrient content and young pods probably produce more photosynthate than green seeds. If such is the case, the ideal 100 seed weight would be lower than the seed weight predicted by the function. Also, no account is made for the weight of the peduncle. The peduncle generally is short and light, and it was empirically determined from a small dataset to weigh approximately $10 \%$ of the weight of the pods and seed. Each peduncle can support 2 pods. Generally, only 1-2 peduncles are produced per plant in Montana. If the peduncles contribute significantly to photosynthate then the ideal seed size would be smaller than the seed size predicted by the function. The assumption that the number of pods per plant and seed number can vary at no cost to the plant is probably inaccurate. As only 1-2 pods are produced per node, more nodes must be produced in order to generate additional pods and seed. If producing more nodes significantly drains photosynthate, then the ideal seed size would be larger than predicted by our algorithm.

Some of the parameters used in the function such as seed density, pod density, pod wall thickness, testa thickness, and testa density could be refined because it is likely that these values vary considerably in different genotypes or legume species. However, a change in seed density does not affect the algorithm, and changes in pod density, testa thickness, and testa density also have a rather weak effect on the overall calculations, indicating the function is robust. Doubling pod wall thickness to $0.08 \mathrm{~mm}$ would increase the ideal seed size to $18 \mathrm{~g}$, but empirical evidence indicates that wall thickness used in the function is a good estimate. Huyghe [13] estimated the proportion of pod wall biomass for each pod to be approximately 0.13 , and this study indicates that the proportion of pod wall biomass for each pod is approximately 0.15 . By using the estimate of pod wall thickness in this model $(0.194 \mathrm{~mm})$, the formula for the volume of a cylinder, and the pod wall density, it was determined that the estimate for pod wall biomass per pod produced by the model was only $1 \%$ lower than the empirically determined data. The space between seeds in each pod was also estimated based on the proportion of pod wall biomass measured in this study. Based on the estimates of pod wall biomass, it is estimated that the ratio between space occupied by the seed and dry seed diameter is approximately 1.1. While this estimate could be better defined in future studies, increasing this ratio beyond 1.1 will result in an allocation of more photosynthate to pod wall biomass than was empirically determined and previously reported. 
Finally, our algorithm assumes that the purchase of seed and the use of saved seed have an equal cost to the grower. Typically, growers feel that using saved seed is more economical, but processors often require growers to purchase seed from a specific supplier at a greater cost. If the cost of seed is higher than the cost of the harvested product, the ideal seed size would be smaller than the seed size predicted by this function. The ideal seed size varies depending on the yield potential of a given environment. Smaller expected yields indicate that a smaller seed size is ideal, but higher yielding areas require peas with larger seed sizes to achieve their highest actual yield because harvest index increases with increases in seed size. Processors also may demand larger seed sizes. Larger seed sizes could also be more attractive to consumers. When using the algorithm to determine the economic impacts of seed weight, these factors will deserve more attention.

The algorithm initially assumes that the only variable is seed size, but it does not account for the fact that the seed testa is often peeled from the seed after harvest. The function could be altered to account for the weight of the testa because the weight of the testa per unit of mass will vary depending on the size of the seed. It was determined empirically in this study that the average testa thickness is approximately 0.125 $\mathrm{mm}$ in pea (this estimate was based on a small dataset). A function accounting for testa thickness indicates that the ideal hundred seed weight is $17.5 \mathrm{~g}$ at the average yield potential in Montana. The increase in ideal seed weight when the testa is removed is due to the fact that larger seeds have a smaller surface area per unit of mass than smaller seeds. It is assumed in the model that seed testa has no value.

\section{Conclusions}

The ideal 100 seed weight predicted by this algorithm $(\sim 12.5$ g.) is much lower than the seed weight of current cultivars grown in Montana [17], indicating that efficiency could be increased by decreasing seed size. Based on the output of this function, selecting for individuals with larger seed sizes will increase yield due to increased harvest index, but it will also increase the cost of seed. The point of diminishing returns occurs at approximately $12.5 \mathrm{~g}$. Pea breeders should correct yield results for variations in seed size by using actual yield rather than yield, assuming that there is no premium or requirement for a specific seed size. Additionally, extension publications in peas and other pulses should be reporting actual yield per acre rather than grain yield per acre, when no premium for larger seed exists. Processors who remove the pea seed testa during processing should offer premium prices for larger seeded peas, if the testa is not utilized in other processes. However, for many of the end uses of the dry pea crop such as pea flour and split peas, seed size is likely irrelevant and efficiency could be increased by growing a small seeded variety. Since seed costs are often higher than the cost of harvested seed, it is likely that the ideal seed size is lower than the seed size predicted by this model. This algorithm could be modified to predict the ideal seed size under a wide range of conditions.
The harvest ratio describes the overall efficiency of planting a crop, and a higher harvest ratio is generally beneficial. There are several mechanisms whereby harvest ratio could be increased. Firstly, seeding rate could be decreased. However, yield is often highly dependent on seeding rate. Secondly, seed size could be decreased through breeding, which would reduce the weight of seed planted. Thirdly, the seeding rate could remain the same, but varietal differences in optimum seeding rate could be exploited. It has been shown that branching varieties of peas achieve optimum yield potential at lower seeding rates [18], and the branching habit appears to decrease lodging susceptibility (data not shown). Branched varieties also may be more competitive with weeds [19], which are a consistent problem in pulse crops.

The ideotype for seed size in peas and other large seeded legumes has not been previously defined. It should be noted that a similar analysis would likely be valid in other crops with a low harvest ratio, such as chickpea and bean, if no premium for seed size exists. Particularly in chickpea, consumer preferences are likely more important than efficiency of production; however, defining the ideotype for seed size in peas and other large seeded legumes may allow crop breeders and agronomists to increase efficiency of cropping systems for end uses where seed size is of no importance.

\section{Disclosure}

The current address of Jamin Smitchger is as follows: Department of Crop and Soil Sciences, Washington State University, P.O. Box 646420, Pullman, WA 99164, USA. Jamin can be contacted via e-mail at jsmitchger@wsu.edu.

\section{Conflicts of Interest}

The authors declare that the research was conducted in the absence of any commercial or financial relationships that could be construed as potential conflicts of interest.

\section{Acknowledgments}

The senior author would like to thank the MSU Graduate School for funding a Ph.D. Completion Award on his behalf. Funding was also provided by the Northern Pulse Growers Association, AGT Foods USA, and the USDA Hatch Act.

\section{Supplementary Materials}

The function to identify the ideal seed size was created in a Microsoft Excel spreadsheet (the equation predicting the ideal pod length is on the first sheet of the spreadsheet). Once the file is opened, yield potential, seed cost, pod length, or seeding density can be changed to a single value in all the cells in any green column and the effect on ideal seed size can be visualized. Once the algorithm is understood, the function could be modified for other species. (Supplementary Materials) 


\section{References}

[1] G. M. Timmerman-Vaughan, A. Mills, C. Whitfield et al., "Linkage mapping of QTL for seed yield, yield components, and developmental traits in pea," Crop Science, vol. 45, no. 4, pp. 1336-1344, 2005.

[2] "NASS, "Pea," National Agricultural Statistics Service," 2017, http://www.nass.usda.gov.

[3] J. S. Pate, P. J. Sharkey, and C. A. Atkins, "Nutrition of a Developing Legume Fruit: Functional Economy in Terms of Carbon, Nitrogen, Water," Plant Physiology, vol. 59, no. 3, pp. 506-510, 1977.

[4] B. T. Biger, "The effect of seed size on yield and yield components of chickpea and lentil," African Journal of Biotechnology, vol. 8, no. 8, pp. 1482-1487, 2009.

[5] M. Gusmao, K. H. M. Siddique, K. Flower, H. Nesbitt, and E. J. Veneklaas, "Water Deficit during the Reproductive Period of Grass Pea (Lathyrus sativus L.) Reduced Grain Yield but Maintained Seed Size," Journal of Agronomy and Crop Science, vol. 198, no. 6, pp. 430-441, 2012.

[6] D. J. Bing and Q. Liu, "Investigation of relationships of yield, seed size, seed protein and starch content and development of varieties with improved protein content of field pea (Pisum sativum L.)," Canadian Journal of Plant Science, vol. 91, pp. 381381, 2011.

[7] L. Irzykowska and B. Wolko, "Interval mapping of QTLs controlling yield-related traits and seed protein content in Pisum sativum," Journal of Applied Genetics, vol. 45, no. 3, pp. 297-306, 2004.

[8] P. Krajewski, J. Bocianowski, M. Gawłowska et al., "QTL for yield components and protein content: A multienvironment study of two pea (Pisum sativum L.) populations," Euphytica, vol. 183, no. 3, pp. 323-336, 2012.

[9] G. M. Timmerman-Vaughan, J. A. McCallum, T. J. Frew, N. F. Weeden, and A. C. Russell, "Linkage mapping of quantitative trait loci controlling seed weight in pea (Pisum sativum L.)," Theoretical and Applied Genetics, vol. 93, no. 3, pp. 431-439, 1996.

[10] V. Kosev and A. Mikić, "Short communication. Assessing relationships between seed yield components in spring-sown field pea (Pisum sativum L.) cultivars in bulgaria by correlation and path analysis," Spanish Journal of Agricultural Research, vol. 10, no. 4, pp. 1075-1080, 2012.

[11] B. L. Gambín and L. Borrás, "Resource distribution and the trade-off between seed number and seed weight: A comparison across crop species," Annals of Applied Biology, vol. 156, no. 1, pp. 91-102, 2010.

[12] C. M. Donald, "A barley breeding programme based on an ideotype," The Journal of Agricultural Science, vol. 93, no. 02, p. 261, 1979.

[13] C. Huyghe, "Genetics and genetic modifications of plant architecture in grain legumes: A review," Agronomy for Sustainable Development, vol. 18, no. 5-6, pp. 383-411, 1998.

[14] A. M. Flinn and J. S. Pate, "A quantitative study of carbon transfer from pod and subtending leaf to the ripening seeds of the field pea (Pisum arvense L.)," Journal of Experimental Botany, vol. 21, no. 1, pp. 71-82, 1970.

[15] V. O. Sadras, "Evolutionary aspects of the trade-off between seed size and number in crops," Field Crops Research, vol. 100, no. 2-3, pp. 125-138, 2007.

[16] M. Reynolds, J. Foulkes, R. Furbank et al., "Achieving yield gains in wheat," Plant, Cell \& Environment, vol. 35, no. 10, pp. 17991823, 2012.
[17] Y. Mohammed and C. Chen, "2016 Montana Cool-Season Spring Pulse Variety Evaluation Annual Report, Montana Agricultural Experiment Stations 2016 Annual Report," 2016.

[18] J. M. Spies, T. Warkentin, and S. J. Shirtliffe, "Basal branching in field pea cultivars and yield-density relationships," Canadian Journal of Plant Science, vol. 90, no. 5, pp. 679-690, 2010.

[19] J. M. Spies, T. D. Warkentin, and S. J. Shirtliffe, "Variation in field pea (pisum sativum) cultivars for basal branching and weed competition," Weed Science, vol. 59, no. 2, pp. 218-223, 2011. 


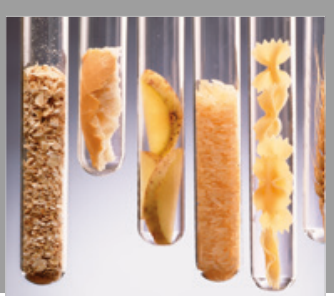

International Journal of Food Science

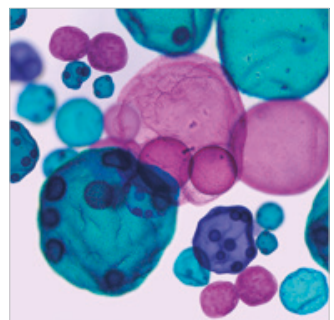

International Journal of Microbiology
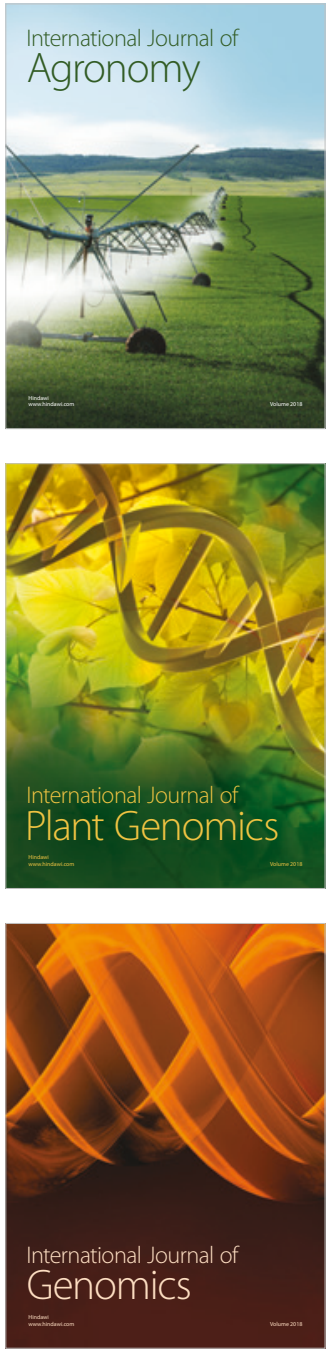

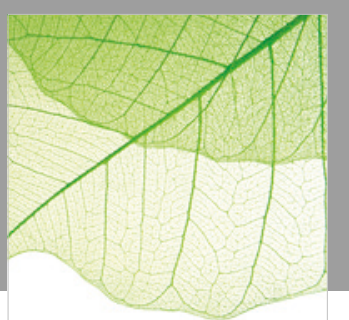

Journal of Botany
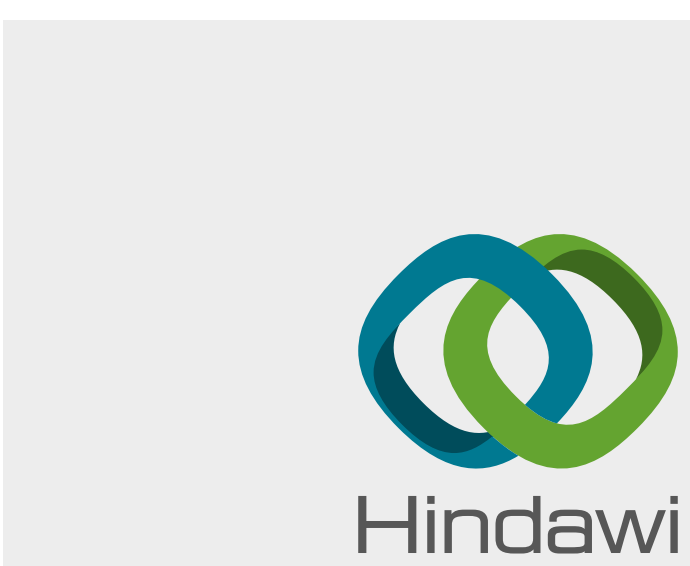

Submit your manuscripts at

www.hindawi.com
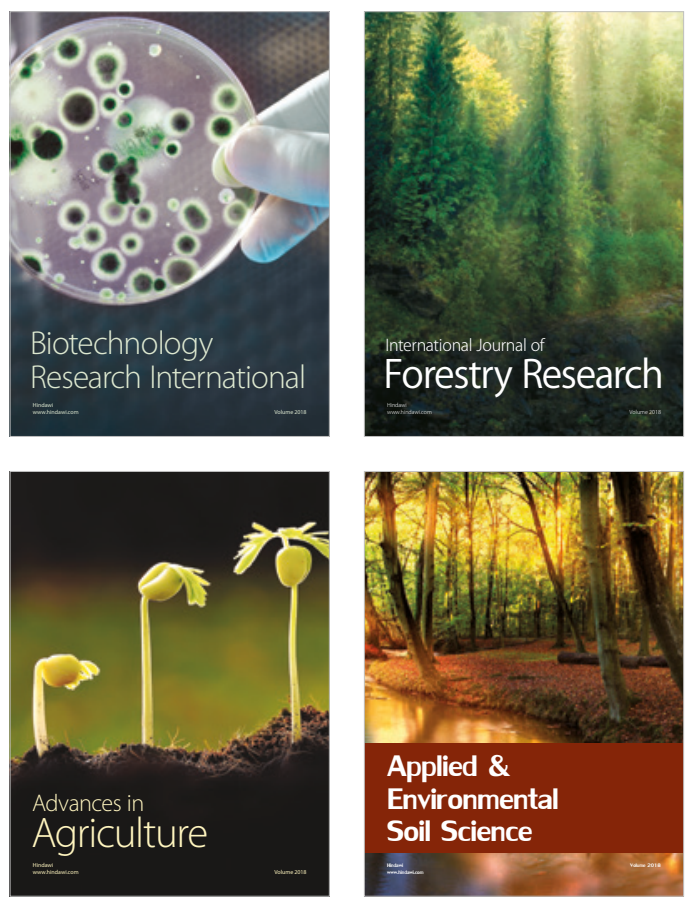

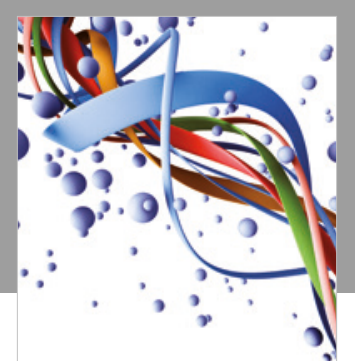

Scientifica

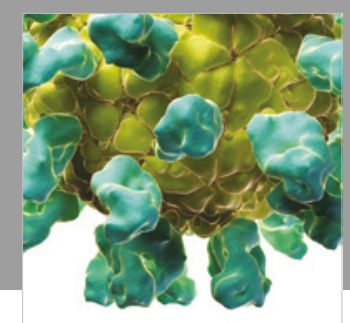

Veterinary Medicine International

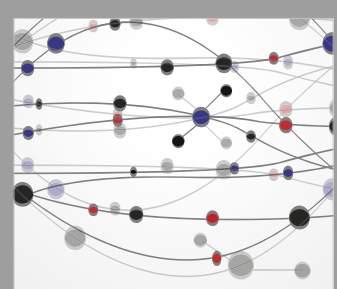

The Scientific World Journal
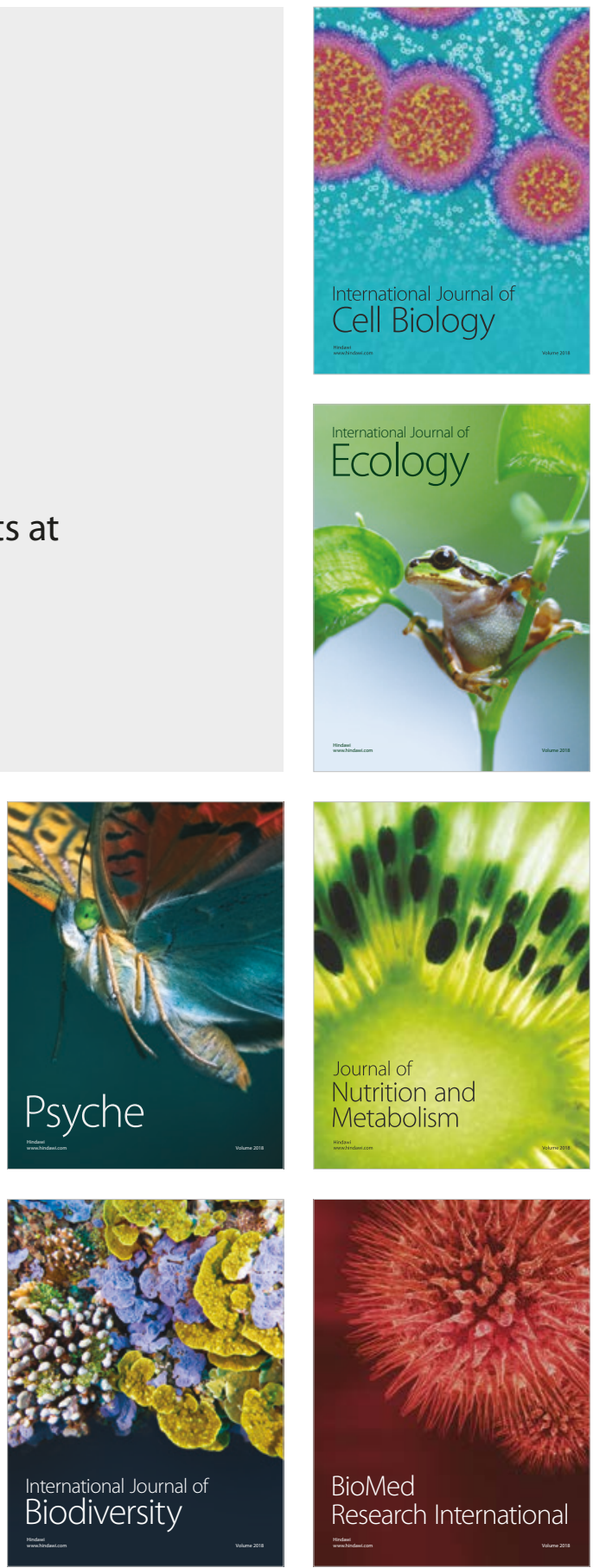